\title{
Interconsulta psiquiátrica na pediatria
}

\author{
M aria Lucrécia Scherer Zavaschia, Dênio Lima ${ }^{b}$ e Regina Beatriz Palma
}

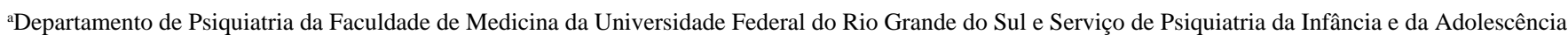
do Hospital de Clínicas de Porto Alegre. bérea de Psiquiatria da Faculdade de Medicina da Universidade de Brasília

\section{Introdução}

A consultoria psiquiátrica dirigida ao atendimento de crianças e adolescentes e a "liason" com outros profissionais de saúde, tem sido longamente recomendada como parte integrante e essencial do trabalho do psiquiatra da infância e adolescência inserido no contexto do hospital geral.

No Brasil, emprega-se o termo interconsulta psiquiátrica, de forma genérica, em lugar de "consultation - liason psychiatry", para designar as ações desempenhadas pelos profissionais de saúde mental junto a outros profissionais no hospital geral.

A definição tradicional considera que consultoria se refere à atuação do psiquiatra infantil na avaliação do paciente e na formação de hipóteses e de recomendações oferecidas às equipes solicitantes, que atendem pacientes pediátricos. No trabalho de "liason", o psiquiatra de crianças e adolescentes envolve-se mais diretamente no atendimento do paciente, inclusive atuando como membro da equipe. ${ }^{1-4}$

A interconsulta em pediatria iniciou-se com Léo Kanner ${ }^{5}$ na década de 30 no John's Hopkins Hospital. Atualmente, a maioria dos hospitais de médio e grande porte nos Estados Unidos conta com serviços de interconsulta.

No Brasil, o censo nacional realizado na década de 1990 revelou que serviços de interconsulta encontram-se disponíveis em $86 \%$ dos 63 hospitais gerais que contam com serviço de psiquiatria. $^{6}$

Estima-se, que 2/3 dos pacientes admitidos em serviços de pediatria seriam beneficiados pela consultoria psiquiátrica. Entretanto, a solicitação de consultoria pelos pediatras se situa na faixa de $11 \% .^{5}$

Dados quanto à diminuição do tempo de recuperação e de hospitalização, bem como quanto à maior aderência ao tratamento em pacientes beneficiados pelo serviço de interconsulta, confirmam a relevância deste trabalho. ${ }^{2,6}$

\section{Abrangência da interconsulta psiquiátrica na pediatria}

A interconsulta psiquiátrica dirigida à pediatria abrange a assistência à criança e ao adolescente, assim como a seus pais, familiares e equipes envolvidas no cuidado destes pacientes.

Ao enfoque individualizado do paciente deve ser acrescida uma abordagem psicodinâmica, que envolva o funcionamento da família e da equipe.

Observar a interação do paciente, pais e equipe e escutar atentamente a história de cada um auxilia na formulação de hipóteses e na elaboração de estratégias de intervenção.

É fundamental que o consultor psiquiátrico dentro da unidade pediátrica assuma uma postura médica interando-se da história clínica, dos exames complementares, da fisiopatologia, da evolução, do prognóstico e das formas de tratamento propostas aos pacientes. Somente de posse dessas informações poderá ter condições de elaborar diagnósticos diferenciais, que muitas vezes envolvem manifestações psiquiátricas de doenças orgânicas.

\section{Reações da criança à hospitalização}

A reação da criança diante da doença está diretamente relacionada a múltiplos fatores, tais como idade, estresse imediato representado pela dor física desencadeada pela doença, angústia de separação devido à hospitalização, traços de personalidade, experiências e qualidade de suas relações parentais. ${ }^{7,8}$

Para Bowlby, a percepção e a conduta da criança são influenciadas pela atitude dos pais que, por sua vez, é determinada pela postura geral do médico frente à patologia. ${ }^{9}$

$\operatorname{Trad}^{7}$ considera também que a equipe hospitalar, pelo seu papel esclarecedor e atitude continente, oferece aos pais da criança gravemente enferma condições necessárias para que possam suportar e compreender a reação do filho à própria doença. Essa reação varia de acordo com seu nível de compreensão, decorrente da fase evolutiva em que se encontra. Assim, somente à medida que a criança amadurece, sua concepção da doença vai ficando mais ampla e complexa. Até os 3 anos de idade a criança apresenta dificuldade de separar-se de seus pais. Quando isso ocorre, demonstra aflição e desespero. Há uma concordância entre os autores de que os efeitos mais prejudiciais da hospitalização ocorrem nos pacientes dessa faixa etária. ${ }^{7,9-11}$ Spitz ,em 1946, ${ }^{11}$ descreveu o quadro clínico que denominou de "depressão anaclítica", no qual a criança afastada da sua mãe apresenta inicialmente um período de choro e gritos incessantes entendidos como manifestação de protesto diante da separação. Caso a mãe não retorne ou não seja substituída por outra figura de apego, em poucas horas, a criança pode evoluir para um quadro de apatia com recusa do contato ou indiferença aos circunstantes.

A expressão da angústia do bebê é visível pela alteração de seu sono ou de sua atividade física. Se um bebê de cinco meses, por exemplo, for separado de seus pais, ficando sozinho em um centro de tratamento intensivo pediátrico (CTIP), pode apresentar uma atitude de hipervigilância, traduzida por um comportamento excessivamente voltado ao meio externo. São aqueles bebês que apresentam gestos desorganizados e olhar perdido como se buscassem algo de forma incessante. ${ }^{8}$ Paulo, 4 meses evoluindo bem de um quadro de septicemia. Durante a madrugada, iniciou quadro de agitação: debatendo-se no berço, cuspindo o bico, recusando a mamadeira. Não fixava o olhar em 
nada, assumindo uma postura hipervigilante com visíveis sinais de sofrimento. Foram feitas reiteradas tentativas por parte da equipe no intuito de acalmar o bebê. Finalmente, optou-se por interromper o descanso da mãe, que se encontrava exausta após inúmeras noites de vigília. Paulo no colo de sua mãe acalmouse rapidamente e em poucos minutos adormeceu. A equipe da CTIP aprendeu com Paulo que o maior tranqüilizante para um bebê é a presença de sua mãe ou de alguém que a represente.

Portanto, o grupo que atende a criança doente necessita considerar que a presença real da mãe tem um papel tranquiilizador para o pequeno paciente. Anna Freud ${ }^{8}$ entende que nessa situação o progenitor funciona como um Ego substituto, pois a criança por si só não consegue dominar sua ansiedade, devido a sua limitada capacidade de compreender o que está ocorrendo. Ao longo do desenvolvimento, a criança amplia a noção de seu próprio corpo, porém angustia-se com ferimentos, desejando cobri-los, como temendo esvair-se, imaginando assim prevenir a perda de fluidos ou órgãos internos. ${ }^{8}$ Marcos -5 anos - internado na CTIP com quadro de cetoacidose diabética. Ao coletar sangue, chorava quando o êmbolo da seringa se enchia e não no momento da picada da agulha. Referiu para a equipe que a picada praticamente não doía, mas que chorara por temer que seu sangue não parasse nunca mais de sair. Foi necessário que o médico esclarecesse o paciente, de acordo com sua capacidade cognitiva, sobre o funcionamento anatômico do organismo. Marcos então tranqüilizou-se compreendendo que não perderia parte alguma de seu corpo.

$\mathrm{Na}$ idade escolar, dos seis aos 11 anos, ${ }^{8}$ a criança já se encontra em condições intelectuais de compreender melhor seu corpo, sua doença e o conceito de irreversibilidade da morte. Para lidar com a ansiedade que a doença provoca, mobiliza o que se chama de "defesas da linha obsessiva", valendo-se de intelectualizações, racionalizações e "anestesia" dos sentimentos. Gabriela - 8 anos - apresenta insuficiência renal crônica e é capaz de descrever para os membros da equipe, com precisão, todos os passos necessários para instalação da diálise peritoneal a que é submetida sem, no entanto, parecer estar sofrendo com o procedimento. A equipe foi orientada a não incentivar o relato dissociado da paciente e por outro lado assumir uma postura muito continente, favorecendo uma diminuição dos mecanismos de defesa de Gabriela $e$ aliviando as intensas ansiedades. É comum também encontrarem-se pacientes em idade escolar que, diante da doença, desenvolvem uma reação patológica caracterizada por medos irracionais (sintomas fóbicos) como medo do escuro, da doença e da morte. ${ }^{8}$ Mauro - 10 anos - desenvolveu quadro de peritonite com deiscência de sutura. Submetia-se tranqüilamente aos curativos, mas gritava, chorava e demonstrava reações de desespero quando necessitava punção venosa. Referia que era a pior dor do mundo. A equipe percebeu o deslocamento fóbico do paciente e pode tolerar a sua reação, tentando tranqüilizá-lo durante a punção venosa e usando sedação com benzodiazepínicos quando necessário. Muitas vezes, os efeitos depressivos da enfermidade são tão devastadores que a criança defende-se também com alternativas maníacas, negando os efeitos da doença, agitando-se e até hostilizando e desprezando os pais e a equipe médica. ${ }^{8}$ Laura -13 anos-portadora de tumor abdominal ressecado e com bom prog- nóstico. Fez quadro de infecção de parede abdominal. Inicialmente apática, depressiva. Com o passar do tempo tornou-se agressiva, atirando objetos longe e dizendo "nomes feios" para os membros da equipe. Neste caso, a defesa contra o sofrimento, vivido como um ataque ao próprio corpo, evoluiu para um ataque externo, o que propiciou o manejo compreensivo desta reação por parte da equipe e dos familiares.

O início da adolescência é marcado por acentuadas modificações somáticas e psíquicas, com o objetivo de alcançar individualidade e identidade próprias. A importância que o corpo adquire nesta etapa do desenvolvimento e a interferência da doença podem tornar o adolescente desconfiado e resistente quando estiver em situações de dependência e de necessidade de ser cuidado por outros. Assim como se depara na vida com a necessidade de lidar com a autoridade, o adolescente traz para a relação com seu médico e com a equipe hospitalar conduta de desafio e tentativas de independência, tendo dificuldades para aceitar as recomendações da equipe por entendê-la autoritária. ${ }^{8}$ Pedro - 17 anos - recentemente submetido a transplante hepático. Mostrou-se envergonhado no momento que necessitava urinar em função da pouca privacidade existente na CTIP. A equipe, percebendo o seu sofrimento com a invasão de sua privacidade, designou um auxiliar de enfermagem do sexo masculino para auxiliar Pedro nesses momentos.

Observa-se que a conduta de crianças e de adolescentes sob o impacto de grave enfermidade pode apresentar-se muito diferente da esperada para sua idade cronológica, podendo regredir a condutas infantis próprias de etapas anteriores do desenvolvimento. Assim, um adolescente pode utilizar mecanismos obsessivos de controle e ansiedades fóbicas, como um escolar, enquanto um escolar pode apresentar profunda ansiedade de separação, como um bebê. ${ }^{8}$ Roberto - 15 anos - foi submetido a transplante renal. Não tolerava que sua mãe se afastasse do quarto por mais de cinco minutos, agitava-se e começava a chorar quase como um bebê. Diante da ansiedade apresentada pelo paciente, a equipe da CTIP foi orientada quanto ao aspecto regressivo do paciente, o que favoreceu uma abordagem mais tolerante e compreensível com Roberto. Permitiu-se a presença constante de um familiar durante toda a internação.

\section{Dinâmica das relações equipe-família frente à doença da criança}

O consultor psiquiátrico deve estar familiarizado com a dinâmica que se desenvolve dentro das unidades hospitalares.

Bastante ilustrativa é a concepção de Woolston e Koumann, ${ }^{12,13}$ autores de trabalhos clássicos sobre a consultoria em CTIP.

Consideram que a CTIP não se resume apenas à equipe médica, de enfermagem e ao paciente, mas deve ser vista e entendida como uma comunidade composta por vários segmentos: família, paciente, enfermagem, ambiente (subcomunidades), com características e "mitologias" próprias. Essas "mitologias" dependem das experiências, com êxito ou não, vividas pelos vários segmentos da comunidade, que terão importante efeito sobre a reação dos indivíduos no presente. Essa reação segue uma seqüência repetitiva, que se inicia com a admissão do paciente e 
que se caracteriza inicialmente por choque e tentativa de negar o estresse. Depois, se estabelece uma batalha contra a doença na tentativa de controlá-la e finalmente ocorre a euforia pelo sucesso ou o luto pela perda. Entretanto, esse processo não ocorre de maneira sincrônica em todos os subsistemas, gerando problemas de comunicação, falta de sintonia, novo estresse e reações mal-adaptativas. Exemplo freqüente desse desencontro ocorre quando o pediatra comunica aos pais um mau prognóstico e esses respondem com negação e hostilidade. Quanto mais o médico insiste em seu prognóstico, mais a família se torna hostil. Entretanto, a resposta dos pais não é inadequada, considerando a situação de grande tensão em que se encontram. De fato, o que ocorre corresponde a uma reação normal dos pais, sendo essa uma primeira etapa da elaboração da perda e do sofrimento.

É comum que o paciente ou familiares utilizem mecanismos de defesa tais como negação, dissociação e projeção. Quando a dor é insuportável ou há conflito na relação dos pais com a criança, a negação pode ser utilizada para evitar entrar em contato com a gravidade da doença. Os familiares muitas vezes dissociam o conhecimento de que dispõem sobre a enfermidade e projetam sobre a equipe a responsabilidade da possível piora do quadro clínico, atribuindo à equipe, por exemplo, retardo no diagnóstico ou nos procedimentos terapêuticos, como causa do mau prognóstico.

Se a equipe não compreender que a família está muito angustiada e por isso se vale de mecanismos de defesa contra a dor psíquica, poderá sentir-se acusada injustamente e passar a tratar os familiares e o paciente com hostilidade, abandonando-os no momento mais difícil. É fundamental que se identifiquem as fantasias distorcidas da família. A equipe deve centrar sua intervenção na informação clara e verdadeira sobre a doença do paciente, procurando manter um balanço cuidadoso entre dirigir essa família para a realidade e, ao mesmo tempo, respeitar que mantenham a esperança, permitindo que usem da negação quando o sofrimento for insuportável, sob pena de abandono precoce da criança.

Respostas comuns da equipe a essas vivências estressantes são o afastamento emocional do paciente, a depressão, o prejuízo do raciocínio clínico e a desumanização do atendimento, além de conflitos entre os membros da equipe.

\section{Solicitações da equipe}

A interconsulta psiquiátrica na pediatria no âmbito hospitalar envolve as seguintes solicitações:

a. nas situações de emergência: geralmente o pediatra pede ajuda para esclarecimento daqueles quadros que envolvem dificuldade de relacionamento e/ou comportamento e requerem uma urgência no atendimento. Dentre as dificuldades encontradas pelo pediatra, existe o risco de suicídio em adolescente, abuso sexual, comportamentos violentos resultante de intoxicação por drogas e álcool e suspeita de psicoses;

b. nos casos em que os exames clínicos e laboratoriais são negativos e doenças neurológicas foram descartadas: o pediatra solicita o auxílio do psiquiatra para identificar transtornos psiquiátricos com manifestações somáticas, como quadros conversivos ou dores psicogênicas, tipo quadros de dores abdominais recorrentes; c. nas doenças crônicas: o interconsultor é solicitado para dar apoio ou suporte nas doenças que requerem tratamento constante e que podem levar os pacientes a transtornos emocionais e não adesão ao tratamento. Rutter et al, ${ }^{14}$ referem que $12 \%$ a $13 \%$ das crianças com doenças crônicas, como diabete, asma e doença de Crohn apresentam problemas emocionais;

d. nos procedimentos invasivos, patologias oncológicas e doenças terminais: crianças com câncer e seus familiares atravessam períodos extremamente estressantes, como nas fases de diagnóstico, recidivas ou finalização de tratamento. Nessas fases podem ocorrer reações psicológicas sérias no paciente e familiares, que podem ser melhor manejadas com o auxílio do interconsultor. ${ }^{15}$ Em outras ocasiões, o psiquiatra pode ser solicitado pela equipe pediátrica para auxiliar crianças e familiares a lidarem com a morte e o luto. Não raramente, o interconsultor identifica situações de luto mal resolvidas, que podem estar gerando problemas emocionais na criança; ${ }^{13,15}$

e. reações importantes em doenças neurológicas: em quadros de meningite ou traumatismos cranianos podem ocorrer quadros de "delirium", que requerem diagnóstico diferencial psiquiátrico e clínico. Em casos de agitação importante, que interfira no tratamento, o uso de antipsicóticos pode ser recomendável;

f. transplante de órgãos: os transplantes de órgãos em pacientes pediátricos são indicados em estágios finais de doenças congênitas ou adquiridas precocemente na vida. Esses pacientes apresentam prejuízos importantes em seu desenvolvimento físico e emocional causados pela doença. O interconsultor é solicitado em serviços pediátricos de transplante de órgãos para auxiliar no atendimento desses pacientes e de suas famílias. A atuação nessa área implica utilização de técnicas de terapia familiar, terapia individual e de conhecimentos de psicofarmacologia. ${ }^{13}$

\section{Conclusão}

Em contextos de tensão e de sofrimento é fundamental o papel do interconsultor psiquiátrico, auxiliando e servindo de suporte para a equipe responsável pelo paciente, que muitas vezes perde sua capacidade decisória, seu equilíbrio emocional e sua habilidade de conduzir a situação. $O$ interconsultor nesses momentos deverá lançar mão de seus conhecimentos éticos, psicodinâmicos e humanos para poder cuidar também dos cuidadores. Necessita desempenhar vários papéis. Deve servir como facilitador de encontros semanais entre os membros da equipe para propiciar a emergência de sentimentos, auxiliar no entendimento das reações da família, da equipe e da criança, de acordo com sua faixa etária, e auxiliar na identificação e no manejo de reações mal adaptativas ao estresse. Deve estar disponível para avaliar pacientes e suas famílias. Cabe ao interconsultor diagnosticar psicoses orgânicas e não orgânicas, avaliar risco de suicídio, problemas de conduta e quadros depressivos, recomendando ou instituindo tratamento medicamentoso, quando necessário. Idealmente, deveria ter um contato diário com a unidade, para estar disponível nos momentos de crise e assim desenvolver seu trabalho junto à equipe. 


\section{Referências}

1. Botega NJ, Cassorla RMS. Encaminhamento ao psiquiatra e relação médico paciente. Rev ABP-APAL 1991;13(2):53-8.

2. McFadyen A, Broster G, Black D. The impact of a child psychiatry liason service on patterns of referral. Br J Psychiatry 1991;158:93-6.

3. Lipowski ZJ. Consultation - liason psychiatry: the first half century. Gen Hosp Psychiatry 1986;8:305-15.

4. Burket RC, Hodgin JD. Pediatrician's perception of child psychiatry consultations. Pschosomatics 1993;34(5):402-8.

5. Reckziegel L, Escosteguy N, Picon P. Consultoria psiquiátrica infantil no HSL-PUCRS: perfil dos pacientes. R Med PUCRS 1999:9(1):4-10.

6. Martins LAN, Botega NJ. Interconsulta psiquiátrica no Brasil: desenvolvimentos recentes. Rev ABP-APAL 1998;20(3):105-11.

7. Trad PV. Infant and childhood depression: developmental factors. New York: John \& Sons; 1987.

8. Zavaschi ML, Bassols AM, Sanchez PC, Palma RB. A reação da criança e do adolescente à doença e a morte - aspectos éticos. Bioética 1993;1:165-72.
9. Bowlby J. Attachment and loss. New York: Basic Books; 1973.

10. Mahler MS, Pine FV, Bergman A. O nascimento psicológico da criança: simbiose e individuação. Rio de Janeiro: Zahar; 1977.

11. Spitz RA. O primeiro ano de vida: um estudo psicanalítico do desenvolvimento normal e anômalo das relações objetais. São Paulo: Martins Fontes; 1980.

12. Woolston JL. Psychiatric aspects of a pediatric intensive care unit. Yale J Biol Med 1984;57:97-110.

13. Woolston JL.General systems issues in child and adolescent consultation and liaison psychiatry. Child Adolesc Psychiatr Clin North Am 1994;3(3):427-37.

14. Rutter M, Tizard J, Whitmore K. Education, health and behavior. London: Longmans; 1970.

15. Lewis M. Psiquiatria infantil e pediatria. In: Tratado de psiquiatria da infância e adolescência. Porto Alegre: Artes Médicas; 1995. p. 9531.016 .

Correspondência: Maria Lucrécia Scherer Zavaschi

Serviço de Psiquiatria do Hospital de Clínicas de Porto Alegre

Rua Ramiro Barcelos, $23504^{\circ}$ andar - 90035-003 Porto Alegre, RS - Tel.: (0xx51) 316-8294/316-8413 - Fax: (0xx51) 316-8294

E-mail: zavaschi@zaz.com.br 